Urban Water Systems \& Floods II 49

\title{
IMPACT ANALYSIS OF THE PRECISION OF MAPPING OPERATIONAL CONDITIONS OF THE WATER SUPPLY SYSTEM ON THE ACCURACY OF HYDRAULIC MODEL CALIBRATION
}

\author{
IZABELA ZIMOCH \& EWELINA BARTKIEWICZ \\ Faculty of Energy and Environmental Engineering, Silesian University of Technology, Poland
}

\begin{abstract}
Hydraulic modelling of water supply network using mathematical simulation models gives a quick response to questions about network operational conditions. These would be complicated and timeconsuming based on study of real water supply network. Due to computer models, the water supply network manager has the ability to analyse the variability of hydraulic parameters in the assumed time of simulation. Hydraulic models are becoming more popular, thanks to their simplicity and results presentation. They allow simulation and analysis of various operational variants (including failure events) to support management of water pipe network and to build Water Safety Plans. Creating such models is a complex task requiring data verification and adoption of certain assumptions, to ensure accuracy. Data entered into the model can be divided into two groups: technical data defining the physical characteristics of the pipe network, e.g. pipes and tanks diameters and operational data describing the dynamics of operation of water distribution subsystem, such as controlling pumps or daily water consumption patterns. However these models are not used for analysis which supports present management of water supply system but they constitute only the basis for dynamic models. The accuracy of dynamic model depends on operational data. Verification of these data and creation of dynamic models require the analysis of water flow quantity and water pressure as well as emergency events from the considered period. Detailed input data allows to increase the precision of obtained results and their accurate interpretation. This paper presents the analysis of operational data and the simulation results of hydraulic parameters (flow and pressure) for the one of the largest in Poland water supply system. In the study the hydraulic model of the Silesian Water Distribution System as well as the data obtained from the GIS and SCADA databases were used.

Keywords: Water Supply System modelling, extended period simulation, data quality, operational data, EPANET 2.0.
\end{abstract}

\section{INTRODUCTION}

Water Supply System (WSS) management is an interdisciplinary task, requiring technical and managerial knowledge. As part of this task, a number of subtasks should be implemented such as: full coverage of drinking water demand, providing water of appropriate quality, water supply under appropriate pressure, prevention of pipes failures, modernization, prevention of water losses, etc. Until recently, water supply companies have been guiding this tasks based on experience and intuition. However, along with technological and IT development, many companies, including WSS, started to introduce new technologies to monitor and support management. ITC systems usually consist of three modules: monitoring (SCADA, CIS), databases (GIS) and an analytic module. The most important from the point of view of WSS managing is the last module, which contains the mathematical simulation model of WSS and optimization algorithms. The well-known models are hydraulic models for calculating water flows and pressure in the pipe network. Building and calibration of the WSS model is a complex and multi-stage process. In the literature, we can find a lot of advice on the mathematical model building and calibration, including importance of data quality and validation data quality, common mistakes in calibration and the latest calibration methods 
[1]-[10]. An important element is the data quality and the relationship between network parameters and data. Many authors focus on the calibration of pressure and pressure dependence on water demand [1], [11]-[15]. This is highly significant for the urban water supply networks, but in larger water supply units modeling it should focus on both pressure drops and water flow rates. This is a common problem in hydraulic design.

Hydraulic and quality models are the basic tool for conducting analyses, including water flow and velocity analysis, pressure changes, water quality changes [16]. The most common analyses include flow rates and pressure changes, on the basis of which it is possible to determine whether a given system (subsystem) works properly, identify weak points of the water supply network, identify areas that need to be reconstructed or modernized or plan to introduce control valves (reducers, pumping stations) [17]. Moreover, the analysis of energy consumption in the water distribution system is increasingly frequent, which is carried out using mathematical models and are the basis for optimizing energy consumption [18]-[21]. Models of water quality changes are used to identify areas at risk of contamination or the risk of losing a certain quality. The most common water quality model is chlorine decay and the disinfection by-products (DBPs) formation, but with the help of a mathematical model, it is also possible to model other water contamination (incidental, intentional) [22]-[25]. Then, the water composition analyses can be used for risk management in Water Safety Plans. However, creating such mathematical models is a difficult and complex task that requires engineering knowledge of hydraulics and modeling, as well as different levels of data quality [26].

The purpose of the work is to indicate the significance of input data to the model, especially operational data for the precision of its calibration. The work presents the influence of WSS control changes on the accuracy of the calibration of the hydraulic model of Silesian Water Supply System

\section{PRINCIPLES OF BUILDING A HYDRAULIC MODELS}

\subsection{Model calculations}

Hydraulic models are described by linear and non-linear algebraic equations, similar to equations describing the current and voltage balances of currents in electric networks and resulting from I and II of Kirchhoffs law. To formulate the equations of the model, it is necessary to determine the spatial structure of the water supply network, which consists of nodes and sections. The first group includes: junctions, tanks, reservoirs. The second group includes: pipes, valves, and pumps. Two hydraulic variables are associated with network elements, namely flow rates and pressures (heads). To solve the flow continuity and head loss equations at a given point in time, it can be used a hybrid node-loop approach [27], [28]. Assuming that the network consists of $\mathrm{N}$ nodes and NF fixed grade nodes (reservoirs and tanks), then the relationship between flow rate and headloss in the pipe between nodes $i$ and $j$ is defined as eqn (1) [27]:

$$
H_{i}-H_{j}=h_{i j}=r Q_{i j}^{n}+m Q_{i j}^{2}
$$

where: $H_{\mathrm{i}}, H_{j}$ - nodal head at the node $i$ and $j$ respectively; $h_{i j}$ - headloss; $r$ - resistance coefficient; $Q_{i j}$ - flow rate between nodes $i$ and $j ; n$ - flow exponent; and $m$ - minor loss coefficient. The second principle in hydraulic model design that must be met is the flow continuity equation in all nodes, given below: 


$$
\sum_{j} Q_{i j}-D_{j}=0 \quad \text { for } \mathrm{i}=1, \ldots, \mathrm{N},
$$

where: $D_{i}$ - the flow demand at node $i$ including convention, flow into a node is positive; $Q_{i j}$ - flow rate between nodes $i$ and $j$. For a set of know heads at the grade nodes, it is necessary to find solutions for all heads $H_{i}$ and flow rates $Q_{i j}$ solving eqn (1) and eqn (2). The solution uses gradient method which starts with initial approximation of the flow in each pipes, which may not satisfy flow continuity. However, trough successive iteration of the method new nodal heads are found by solving the matrix equation:

$$
\mathbf{A H}=\mathbf{F},
$$

where: $\mathbf{A}$ - an (N x N) Jacobian matrix; $\mathbf{H}$ - an ( $\mathrm{N}$ x 1) vector of unknown nodal heads; $\mathbf{F}$ an $(\mathrm{N} x \mathrm{1})$ vector which contains the net flow imbalance in the node described by eqn (2) and the flow correction factor, determined by the following equation:

$$
F_{i}=\left(\sum_{j} Q_{i j}-D_{i}\right)+\sum_{j} y_{i j}+\sum_{f} p_{i f} H_{f}
$$

where: $y_{i j}$ - the flow correction factor; $p_{i f}$ - the inverse derivative of the pressure loss between the connections of the nodes $i$ (junctions) and fixed grade nodes $f$ (tanks and reservoirs) in relation to the flow; $H_{f}-$ head in fixed grade nodes. The flow correction factor $y_{i j}$ is defined as [27]:

$$
y_{i j}=p_{i j}\left(r\left|Q_{i j}\right|^{n}+m\left|Q_{i j}\right|^{2}\right) \operatorname{sgn}\left(Q_{i j}\right)
$$

When new heads are determined from eqn (3), the updated flow rates can be calculated from:

$$
Q_{i j}=Q_{i j}-\left(y_{i j}-p_{i j}\left(H_{i}-H_{j}\right)\right)
$$

This formula maintains the flow continuity around each node after the first iteration, allowing subsequent calculations.

\subsection{Data collection}

Data collected to build a hydraulic model is divided into two categories: technical and operational. The first group includes data describing the physical properties of the objects, including location, elevation, pipes diameter, length, roughness, age and material, tanks capacity, dimensions, base and water surface elevations (minimum and maximum), valves diameter and purpose (throttle or reduction valve), pumps characteristics and reservoir head [29], [30]. This data group is the basic information needed to build a model and run simulations for steady states. Their detail affects the amount of flowing water and pressure changes in the network. Currently, these data are automatically exported from the GIS (Geographic Information System) database, which makes it much easier to create a simulation hydraulic model and update data [31].

Operational data includes changes in the facilities status related to the conditions changes of daily operation of the system. These data consist of the pump and valve control logic and 
Table 1: Operation data required by facility/equipment type.

\begin{tabular}{|l|l|}
\hline Facility/equipment & Operation data \\
\hline \multirow{3}{*}{ Pumps } & $\begin{array}{l}\text { Pump status (on/off); } \\
\text { Pump controlling tank, pressure, flow, or other; } \\
\text { Set points for pump control }\end{array}$ \\
\hline \multirow{3}{*}{$\begin{array}{l}\text { Pressure regulating } \\
\text { valves }\end{array}$} & $\begin{array}{l}\text { Upstream/downstream pressure; } \\
\text { Valve position and setting; } \\
\text { Valve controlling tank, pressure, flow, or other; } \\
\text { Set points for valve }\end{array}$ \\
\hline \multirow{3}{*}{ Flow control valves } & $\begin{array}{l}\text { Valve position; } \\
\text { Flow setting; } \\
\text { Valve controlling tank, pressure, flow, or other; } \\
\text { Set points for valve }\end{array}$ \\
\hline Node pressure & $\begin{array}{l}\text { Any pressure data collected at pressure-monitoring stations in } \\
\text { the distribution system }\end{array}$ \\
\hline Pipe flow & $\begin{array}{l}\text { Any in-line flow data measured in the distribution system } \\
\text { (includes wholesale supply locations or zone boundary meters) }\end{array}$ \\
\hline
\end{tabular}

settings for pumps, control valves and reducing valves, as well as daily consumption patterns (diurnal curves). Typical control data are listed in Table 1.

The WSS does not always work as it was designed. Therefore, during the calibration process the cooperation with the operating staff makes it easier to understand the WSS operational work and allows for a more accurate representation of it in the hydraulic model. Operational data must contain dispatcher activities and permanent system behaviors collected from the considered period. Consequently, monitoring systems (CIS - Customers Information System, SCADA - Supervisory Control and Data Acquisition) are an important source of operational data. The use of these systems makes it possible to determine the switching of pumps or valves, e.g. due to the level of water in tanks. Many hydraulic modeling software packages include a control scheme that maps the behavior of the SCADA system. This function allows the valve to be automatically repositioned or the pump status in response to changes in pressure, flow, water level in a given period of time at certain points in the model [29]. However, monitoring systems the most important task is to provide water demand data. Based on this data, the diurnal curves can be made. Water consumption patterns may vary depending on the customer classes (residential, industrial, commercial) and season [32]-[34], therefore, the use of data from monitoring systems allows the creation of real water consumption patterns that can replace a typical literature curves.

\section{RESEARCH OBJECT}

The research object is the biggest collective Silesian Water Supply System in Poland, which supplies water to over 3 million customers. It is located in the southern-west of Poland in Silesian region. The area covered by the network is hilly with elevation differences equal to $120 \mathrm{~m}$. The system is over $880 \mathrm{~km}$ long with pipes diameters from $50 \mathrm{~mm}$ to $1600 \mathrm{~mm}$. Pipes with diameters from $1100 \mathrm{~mm}$ to $1600 \mathrm{~mm}$ have the largest share, while pipes with diameter below $300 \mathrm{~mm}$ have the smallest share (Fig. 1). Analysed distribution water pipe network is made mainly of steel $(70.6 \%)$, as well as polyethylene (PE, $11.7 \%)$, cast iron $(4.4 \%)$ as well as ductile cast-iron $(3,7)$ and others $(9.6 \%)$. The oldest pipes that build this system come from 1884 (cast iron), and the latest were built at 2016 (PE). 


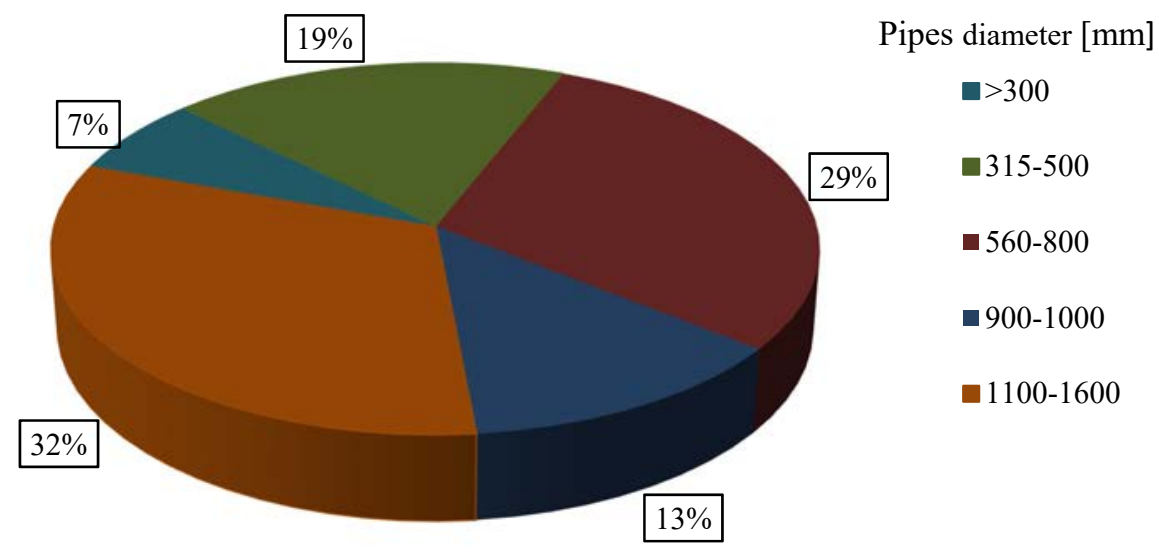

Figure 1: Percentage of pipe diameter of the WSS.

Total average water production is about 330,000 cubic meter per day, which is only $35 \%$ of designed WSS performance. Due to the closure of large factories and reduction of water consumption by productions companies, the water production of this WSS has dropped in last 10 years. The WSS is composed of 11 water treatment plants (WTP), 6 pumping stations and 9 complexes of storage tanks with total capacity of over 374,000 cubic meters (Fig. 2). Water treatment plants, which comprise eight technological lines from WTP_4 to WTP_11 (Fig. 3), produce only $20 \%$ of the daily water demand. However, the biggest daily share in the water production has three water treatment plants WTP_1, WTP_2 and WTP_3, which together deliver to the distribution system about $80 \%$ of the daily water demand. An important role in the analyzed system is played by storage tanks WT_12 and WT_13, they are supplied by WTP_1, WTP_2 and WTP_3, and transport water to the largest area, covering the south-western and north-eastern part of the Silesian region.

The operation of the system is carried out in a continuous control and regulation of flow and pressure. The dispatcher controls the pump and valve settings based on established rules or experience. The daily tasks include maintaining appropriate tank fills and pressure. This system works on various pressures during the day and at night. The main help in network management is the telemetric system (SCADA), which includes all water treatment plants, pumping stations, tanks as well as areas located between supplied facilities. The secondary task is to prevent the lack of water in customers during water-pipe breakdowns, during such events the dispatcher is most often guided by comments from the personnel dealing with damage repair.

\section{HYDRAULIC MODEL OF SILESIAN WSS}

The hydraulic simulation model of the Silesian WSS build based on EPANET 2.0 was used in the study. The model was developed within the framework of NCBiR project POIG.01.03.01-14-034/12. The network graph was exported to calculation software from the GIS database, while the water demand data was exported from the available billing databases (CIS and SCADA). The described procedure is one of the ITC system options supporting the creation of a hydraulic model. 


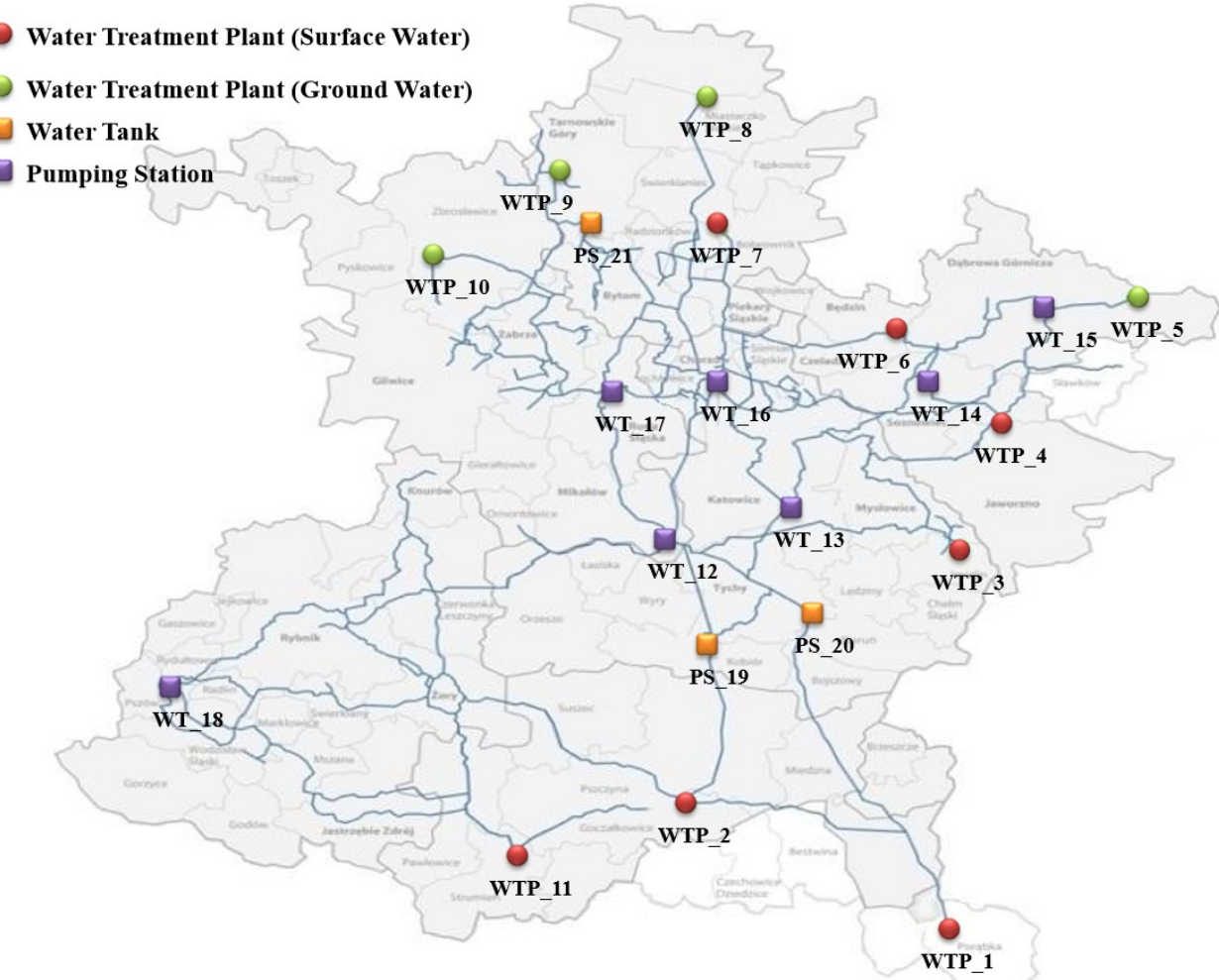

Figure 2: Scheme of the WSS.

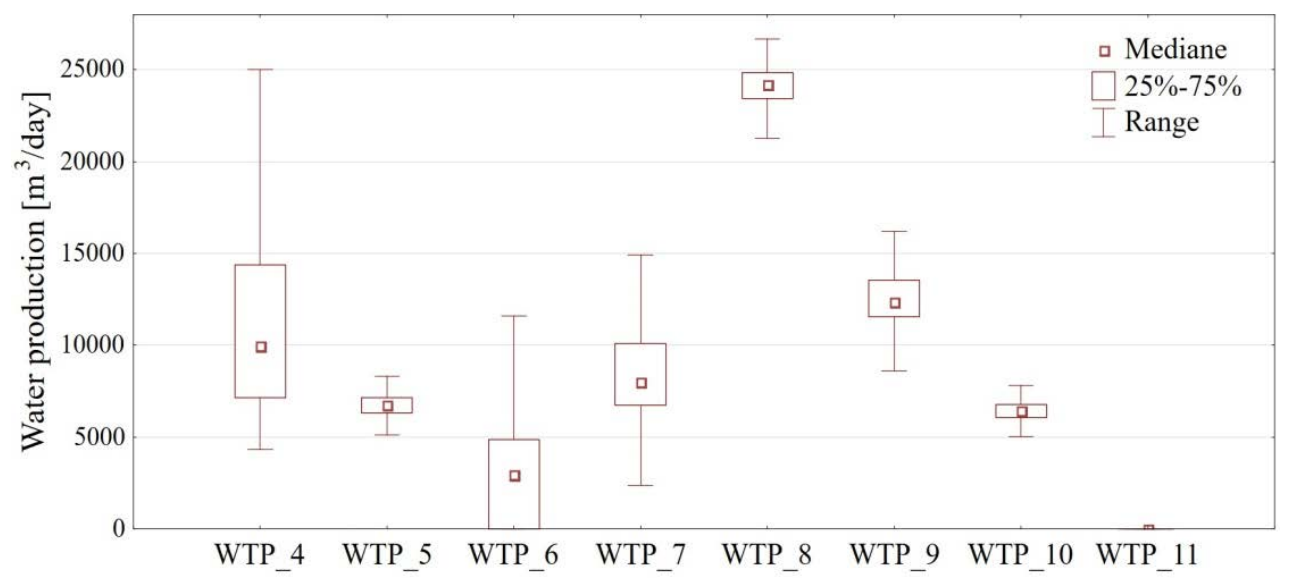

Figure 3: The daily water production in WTPs from no 4 to no 11 in 2016. 


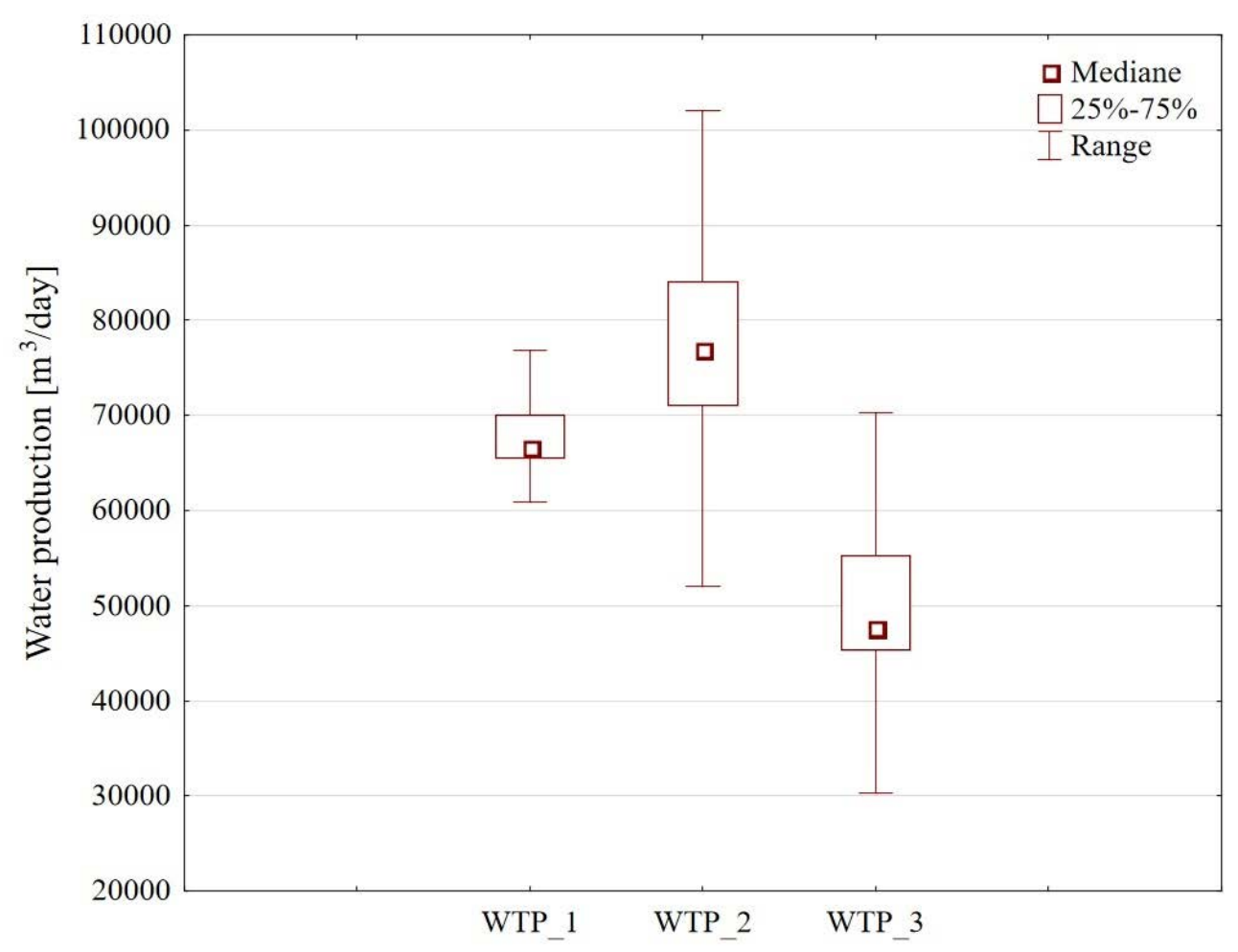

Figure 4: The daily water production in WTP_1, WTP_2 and WTP_3 in 2016.

This mathematical model uses automatic generation of water consumption patterns (diurnal curves) based on CIS system at points covered by this system and based on SCADA system, e.g. from supply points like WTP or tanks, at point without informatics systems. Model is built from 4618 pipes and 6105 nodes, 1609 valves, 90 pumps, 23 tanks and 28 reservoirs. Data for the hydraulic model were exported from databases for one month (October 2016), while calibration and validation were carried out for three days of October (17th, 18th and 19th October). For those days, a high correlation between simulation results and measurements was obtained, $99.3 \%$ for pressures and $97.8 \%$ for flows. Unfortunately, despite good simulation results, the total balance of sold and produced water is negative, at around 41000 cubic meters per day (Fig. 5). In this model, many solutions have been applied that cause "rigid" operation of the system, resulting in the emptying of tanks. These solutions include FCV or PRV valves. This result forces the model to be recalibrated with detailed consideration of operational data.

\section{MODEL RECALIBRATION AND RESULT DISCUSSION}

The most important element to be obtained is the tanks cooperation with the network. In the current model, the most important tanks (WT_12, WT_13, WT_17) do not reach the required water level. Water balance for tanks is $-1656 \mathrm{~m}^{3} / \mathrm{h}$, which confirms that the tanks are empty. The first step in the recalibration of the model was an interview with the dispatcher and employees of the company. As a result, important information about the work of the 


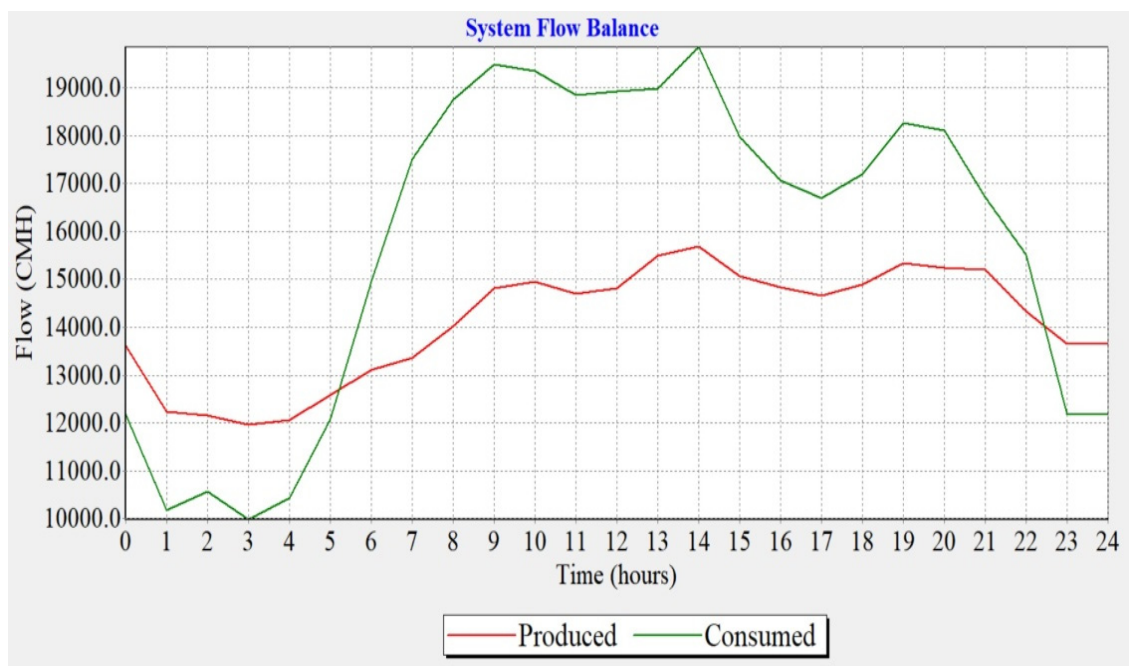

Figure 5: System flow balance for first calibration.

mentioned tanks was obtained. The water supply to the mentioned tanks is regulated by valves, in the case of tanks WT_12 and WT_13 it is a valve located in the area of WT_12. For tanks WT_17, the regulation concerns the water level in tanks, for others it is the pressure height on the valve. The controls procedures for the listed facilities are shown below:

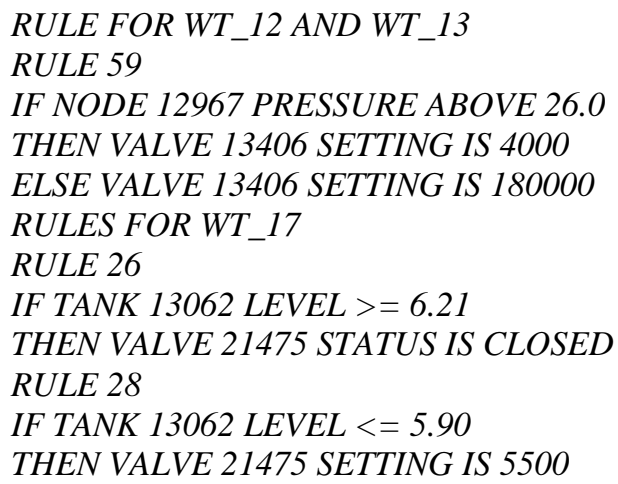

It was also important to regulate the outflow of water from WTP_1 and WTP 2, both stations are regulated based on the filling of tanks in pumping stations PS_19 (WTP_2) and PS_20 (WTP_1). In the original assumption, FCV type valves were introduced without flow control, which resulted in constant water outflow during the day. In recalibration, these valves have been replaced with TCV valves with appropriate setting and controls. The tested model has 30 dedicated controls, Rule-Based type and one Simple Control. All controls have been described based on interviews with company employees. The last step was to verify the diurnal curves. Despite the automatic creation of water demand patterns, some areas were covered by incorrect curves. The cause could be failure of measuring devices or errors in data transfer. The curves were changed for three areas: supplied by PS_19, PS_20 and WT_17. The newly created curves were created based on indications from the three-month monitoring 
system (September, October, November of 2016), in order to avoid errors related to failures of measuring and transmission devices.

As a result, the changes have improved the dynamics of the model. Water balance for tanks is $-40 \mathrm{~m}^{3} / \mathrm{h}$, while the entire system $-2000 \mathrm{~m}^{3} /$ day (Fig. 6). The correlation between simulation and measurement results is $98.8 \%$ for pressures and $98.9 \%$ for flows. For the obtained results (pressures and flow rates) the residual analysis was carried out using Statistica 12 software (Figs 7 and 8). The analysis of the residuals distribution at the assumed significance level for Kolmogorov-Smirnov test $(\alpha<0.1)$ shows that the obtained results (for both flow rates and pressure) have a normal distribution.

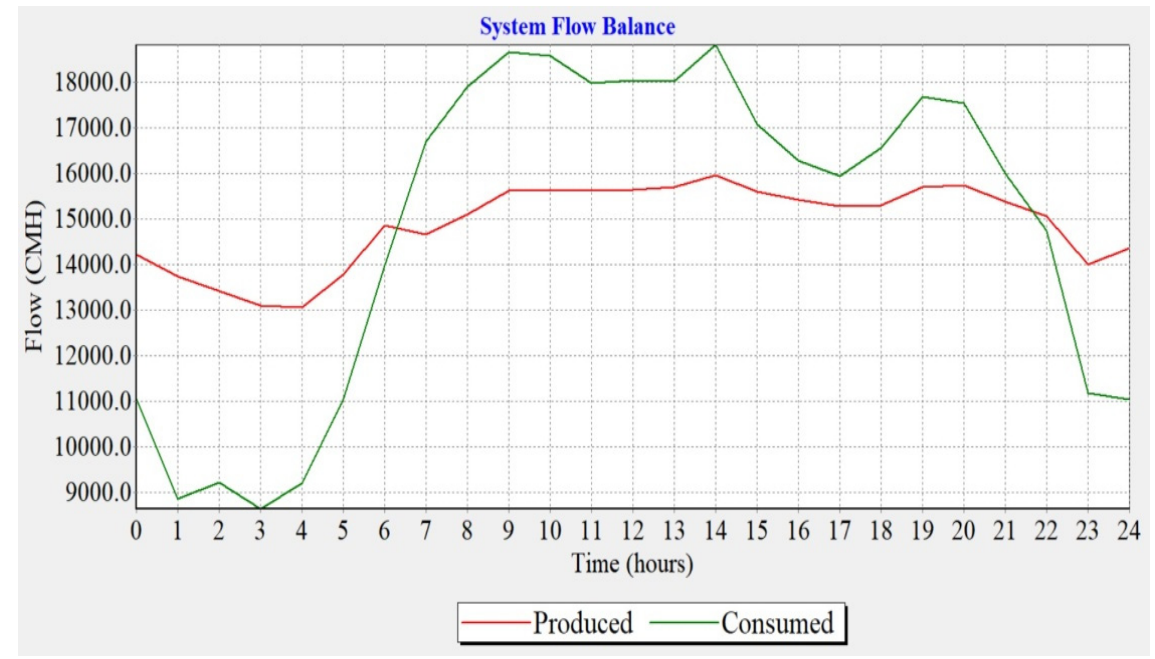

Figure 6: System flow balance after recalibration.

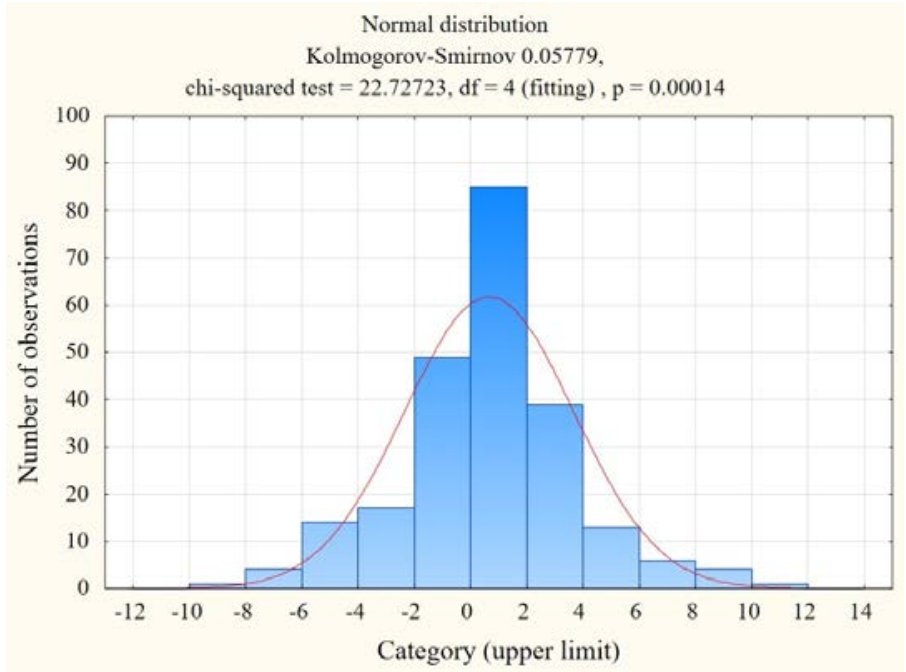

Figure 7: Residual analysis for the pressure correlation results. 


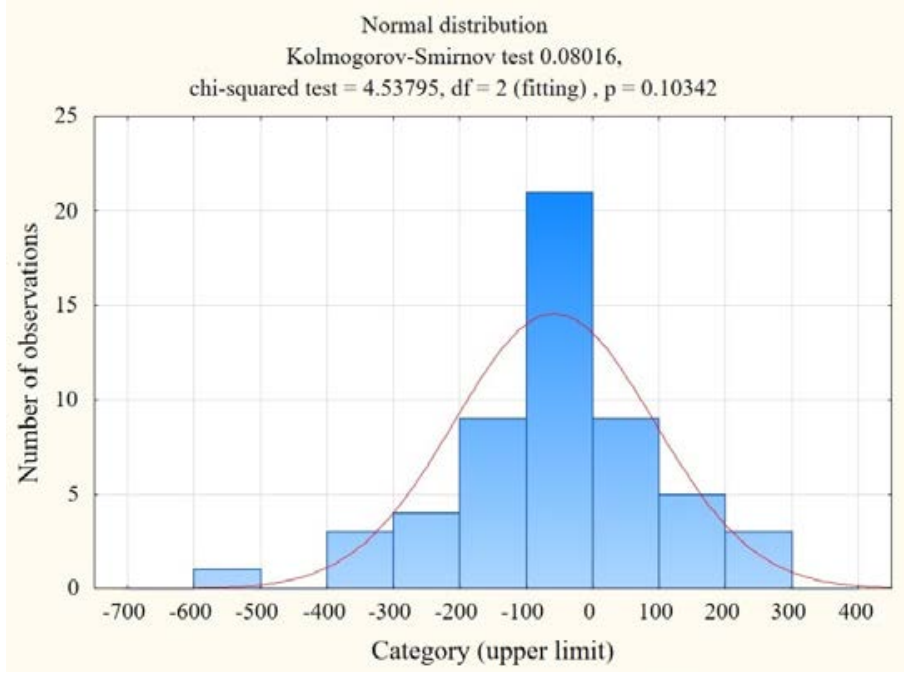

Figure 8: Residual analysis for the flow correlation results.

\section{CONCLUSION}

Mathematical hydraulic models are a useful tool for conducting simulations and analyzes. Their accuracy depends on the detail with which the model was created. Each model can be built and calibrated using rigidly set valves and achieve high compliance. However, such solutions do not provide a dynamic operation of the model, so an important part of building a hydraulic model are operational data. For the analyzed Silesian Water Supply System, by data changes, the model obtained a greater compatibility with the flows, as well as a huge difference in the systems and tanks water balance. Such a model provides more accurate analysis results and can be used primarily for analysis of chlorine distribution or THM formation, as well as for mixing water in the system and in tanks.

\section{ACKNOWLEDGEMENT}

This work was supported by Ministry of Science and Higher Education Republic of Poland within statutory funds - project no BK-286/RIE-4/2017.

\section{REFERENCES}

[1] Cheung, P., Van Zyl, J.E. \& Reis, L., Extension of Epanet for pressure driven demand modeling in water distribution system. Presented at Computing and Control for the Water Industry, University of Exeter Press, 1, pp. 311-316, 2005.

[2] The New Zealand Water \& Wastes Association, National Modelling Guidelines Water Distribution Network Modelling, 2009.

[3] Kapelan, Z., Calibration of Water Distribution System Hydraulic Models. PhD thesis, 2002.

[4] Savic, D.A., Kapelan, Z.S. \& Jonkergouw, P.M.R., Quo vadis water distribution model calibration? Urban Water Journal, 6(1), pp. 1-50, 2009.

[5] Walski, T., Standards for model calibration. Proceedings of the AWWA Computer Conference, Norfolk, 1995. 
[6] Tabesh, M. \& Moeini, R., Calibration of water distribution hydraulic models: A comparison between pressure dependent and demand driven analyses. Urban Water Journal, 8(2), pp. 93-102, 2011.

[7] Bhave, P.R., Calibrating water distribution network models. Journal of Environmental Engineering, 114(1), pp. 120-136, 1988.

[8] Greco, M. \& Del Giudice, G., New approach to water distribution network calibration. Journal of Hydraulic Engineering, 125(8), pp. 849-854, 1999.

[9] Kapelan, Z., Savic, D.A. \& Walters, G.A., Calibration of water distribution hydraulic models using a Bayesian recursive procedure. ASCE Journal of Hydraulic Engineering, 133(8), pp. 927-936, 2007.

[10] Ormsbee, L.E., Implicit network calibration. Journal of Water Resources Planning and Management, 115(2), pp. 243-257, 1989.

[11] Germanopoulos, G., A technical note on the inclusion of pressure dependent demand and leakage terms in water supply network models. Civil Engineering Systems, 2(3), pp. 171-179, 1985.

[12] Giustolisi, O., Savic, D. \& Kapelan, Z., Pressure-driven demand and leakage simulation for water distribution networks. Journal of Hydraulic Engineering, 134(5), pp. 626-635, 2008.

[13] Todini, E., A more realistic approach to the "extended period simulation" of water distribution networks. Advanced in Water Supply Management, Proceedings of CCWI, CRC Press: London, pp. 173-183, 2003.

[14] Soares, A., Reis, K.L. \& Carrijo, I.B., Head-driven simulation model (HDSM) for water distribution system calibration. Advances in Water Supply Management, Proceedings of the CCWI, CRC Press: London, pp. 197-208, 2003.

[15] Tanyimboh, T., Tahar, B. \& Templeman, A., Pressure-driven modeling of water distribution systems. Water Science and Technology: Water Supply, 3(1-2), pp. 255261, 2003.

[16] American Water Works Association, Manual of Water Supply Practices - M32, Computer Modeling of Water Distribution Systems, 4th ed., pp. 6-8, 2017.

[17] Lansey, K.E. \& Mays, L.W., Optimization model for design of water distribution systems. Reliability Analysis of Water Distribution Systems. Part 1: State-of-the-Art, pp. 37-84, 1989.

[18] Su, Y.C., Mays, L.W., Duan, N. \&. Lansey, K.E., Reliability-based optimization model for water distribution systems. Journal of Hydraulic Engineering, 113(12), pp. 1539-1556, 1987.

[19] Ostfeld, A., Reliability analysis of regional water distribution systems. Urban Water, 3(4), pp. 253-260, 2001.

[20] Dnan, N., Mays, L.W. \& Lansey, K.E., Optimal reliability-based design of pumping and distribution systems. Journal of Hydraulic Engineering, 116(2), pp. 249-268, 1990.

[21] Xu, C. \& Goulter, I.C. Reliability-based optimal design of water distribution networks. Journal of Water Resources Planning and Management, 125(6), pp. 352-362, 1999.

[22] Kohpaei, A.J. \& Sathasivan, A., Chlorine decay prediction in bulk water using the parallel second order model: An analytical solution development. Chemical Engineering Journal, 171(1), pp. 232-241, 2011.

[23] Fisher, I., Kastl, G. \& Sathasivan, A., Evaluation of suitable chlorine bulk-decay model for water distribution systems. Water Research, 45(16), pp. 4896-4908, 2011. 
[24] Amy, G.L., Chadik, P.A. \& Chowdhury, Z.K., Developing models for predicting trihalomethane formation potential and kinetics. Journal AWWA, 79(7), pp. 89-97, 1987.

[25] Gallard, H. \& Gunten, U., Chlorination of natural organic matter: kinetics of chlorination and of THM formation. Water Research, 36(1), pp. 65-74, 2002.

[26] Mair, M., Rauch, W. \& Sitzenfrei, R., Improving incomplete water distribution system data. Procedia Engineering, 70, pp. 1055-1062, 2014.

[27] Rossman, L.A., EPANET 2, Users Manual, United States Environmental Protection Agency EPA, pp. 187-188, 2000.

[28] Savic, D.A. \& Walters, G.A., Evolving sustainable water networks. Hydrological Sciences Journal, 42(4), pp. 549-564, 1997.

[29] Walski, T.M., Chase, D.V., Savic, D.A., Grayman, W., Beckwith, S. \& Koelle, E., Advanced Water Distribution Modeling and Management, Bentley Institute Press, pp. 76-106, 2007.

[30] American Water Works Association, Manual of Water Supply Practices - M32, Computer Modeling of Water Distribution Systems, 3rd ed., pp. 17-63, 2012.

[31] Sitzenfrei, R., Möderl, M. \& Rauch, W., Automatic generation of water distribution systems based on GIS data. Environmental Modelling \& Software, 47, pp. 138-147, 2013.

[32] Umapathi, S., Chong, M.N. \& Sharma, A.K., Assessment of diurnal water demand patterns to determine supply reliability of plumbed rainwater tanks in South East Queensland. WSUD 2012: Water Sensitive Urban Design; Building the Water Sensitive Community, Seventh International Conference on Water Sensitive Urban Design. Barton, A.C.T. Engineers: Australia, pp. 1-8, 2012.

[33] CBCL Limited Consulting Engineers, Study on Water Quality and Demand on Public Water Supplies with Variable Flow Regimes and Water Demand, Final Report, 2011.

[34] Carragher, B.J., Stewart, R.A. \& Beal, C.D., Quantifying the influence of residential water appliance efficiency on average day diurnal demand patterns at an end use level: A precursor to optimised water service infrastructure planning. Resources, Conservation and Recycling, 62, pp. 81-90, 2012. 